\title{
О СТАНОВЛЕНИИ ГОТОВНОСТИ К ПРОФЕССИОНАЛЬНОМУ САМООБРАЗОВАНИЮ СТУДЕНТОВ ВУЗА
}

\section{ABOUT BECOMING READY FOR PROFESSIONAL DEVELOPMENT SELF-EDUCATION UNIVERSITY STUDENTS \\ Yu. Kalugin \\ A. Prokhorov}

Summary: The article describes an intelligence experiment related to the system of formation of readiness for professional self-education of University students. The experiment was based on finding out the need for a special manual, its scope, structure and content, as well as the development of tools, identifying the development of the relevant components of the system. The results of the experiment are relevant in modern conditions of distance education.

Keywords: formation of readiness for professional self-education, core interest, interpersonal communication.
Калугин Юрий Евгеньевич

К.п.н., дочент, ФГАОУ ВО «Южно-Уральский государственный университет (национальный исследовательский университет)»

Прохоров Александр Владимирович

К.т.н., доцент, ФГАОУВО «Южно-Уральский государственный университет (национальный исследовательский университет)» prokhorovav@susu.ru

Аннотация: В статье описан разведывательный эксперимент, связанный с системой становления готовности к профессиональному самообразованию студентов ВУЗа. В основу эксперимента было положено выяснение необходимости специального пособия, его объема, структуры и содержания, а также разработки средств, выявления развитости соответствующих компонентов системы. Результаты эксперимента актуальны в современных условиях дистанционного образования.

Ключевые слова: становление готовности к профессиональному самообразованию, стержневой интерес, межличностные коммуникации.

\section{Введение}

$\mathrm{O}$ дной из важнейших задач образования бакалавров является подготовка к профессиональному самообразованию. Это отражается во многих компетенциях. Так в учебных стандартах третьего поколения у ряда направлений существует такая компетенция как «способность к самоорганизации и самообразованию (OK-5)» [1]. Или «способность разрабатывать модели компонентов информационных систем, включая модели баз данных и модели интерфейсов "человек - электронновычислительная машина" (ПК-1)» [2] явно не выполнима без креативности, без приемов самообразования. Такие компетенции возникли в связи с жизненной необходимостью. Так концепция информационно-технической революции «индустрия 4.0» предполагает создание, и эксплуатацию глобальных, сложных, многоуровневых организационно-технических систем, основанных на интеграции в единое информационное пространство физических операций и сопутствующих процессов [3]. Разработка, осуществление, сопровождение и функционирования таких систем требует достаточно многогранных специалистов: знающих, умеющих, с высокой креативностью.

\section{Актуальность, научная значимость работы}

Исходя из вышесказанного, при обучении студентов необходимо формировать в его образовании два на- правления, связанные с самообразованием. Во-первых, учащийся должен уметь сам присваивать новые знания и умения в профессиональной сфере, для чего он должен приобрести навыки самообразовательной деятельности. Во-вторых, у него необходимо развивать креативные умения, стремление к творчеству, к созданию новаций, позволяющих как облегчать и делать более комфортным собственный труд, так и предлагать новшества, позволяющие повысить конкурентоспособность предприятия и его продукции. Для этого у него должна вработаться готовность к профессиональному самообразованию.

Изучение аспектов указанных направлений привело нас к анализу системы готовности к профессиональному образованию, изложенной в [4]. Анализ, в свою очередь, подвел нас к разведывательному эксперименту (по классификации Г.К. Селевко [5]) для проверки некоторых положений, нахождения инструментов и др.

В качестве экспериментальных выступили группа студентов заочной формы обучения. Такой выбор, с одной стороны, привлекателен тем, что учебная деятельность студентов заочной формы обучения наиболее отвечает условиям самообразования [6], с другой стороны, при этом возникают и трудности взаимодействия со студентами, так как заочная форма предполагает минимум официальных встреч с преподавателями. 


\section{Теоретические предпосылки}

Таким образом, в качестве теоретической основы была рассмотрена система готовности личности к профессиональному самообразованию [4].

Готовность личности к профессиональному самообразованию (ГЛПС) - это комплекс всего того, что создает возможность сознательного осуществления индивидом самообразовательных актов профессионального характера. По существу, это система, в которую входят четыре компонента: мотивационно-деятельностный (МД), специальные знания и умения (СЗУ), самоуправленческие умения (СУ) и компонент, называемый внутренней постоянной (ВП). Все эти компоненты должны быть сформированы в сознании индивида в явной или не явной форме. Коротко рассмотрим сущность каждого компонента.

Итак, мотивационно-деятельностный (МД), связанный с мотивацией и самостоятельной работой. Эти две взаимосвязанные составляющие основные, так как без них самообразовательный акт не может реализоваться. Любая самостоятельная работа может осуществляться и продолжаться только тогда, когда она поддержана мотивацией, то есть мотивация - тот мотор, который раскручивает вал самостоятельной работы. В свою очередь, самостоятельная работ - это и есть то, в чем проявляется самообразовательная деятельность. Таким образом, мотивационно-деятельностный компонент определяет разворачивание и осуществление профессиональной самообразовательной деятельности.

При всем разнообразии мотивов нашими исследованиями ранее установлено [7], что доминантными (преобладающими) видами мотивов в самообразовании являются познавательный интерес и задача. Чем они характерны?

Познавательный интерес обусловлен природоопределенными факторами, как правило, коррелирует со специальными способностями и продиктован внутренним состоянием. Задача, как правило, имеет внешнее ситуационное проявление, должна формулироваться и стимулироваться руководством производственной среды.

Что касается самостоятельной работы по освоению объекта самообразования, то она происходит на основе соответствующих знаний и умений и этим данная составляющая связана с другим компонентом, который был назван как специальные знания и умения (СЗУ). Этот компонент является взаимодополняющим для предыдущего. Он включает знания и умения, на основе которых могут совершаться самообразовательные действия, связанные с технической и интеллектуальной обработкой ин- формации об объекте самообразования. Сюда относятся все действия, приемы и методы, позволяющие квалифицированно изучать объект самообразования.

Специальные знания и умения разделяются на профессиональные знания и умения, которые формируются в процессе обучения прфессии, и знания и умения самостоятельной самообразовательной деятельности. Если первые узнаются и отрабатываются в учебной деятельности, то о вторых студентов необходимо информировать, а также проводить тренинг при выполнении заданий.

Причем, центральным действием здесь является понимание, фиксирующее любое промежуточное и конечное состояния, связанные с каждым этапом структуры профессионального самообразовательного акта, и отражается в тех новообразованиях, которые проявляются как элементы личного опыта человека. Понимание глубоко связано с зонами актуального развития и ближайшего развития, о которых скажем позже. Таким образом, специальные знания и умения (СЗУ) - компонент, позволяющий квалифицированно осуществлять профессиональную самообразовательную деятельность, связанный и развиваемый как в профессиональном обучении, так и самостоятельно.

Следующим элементом является самоуправление. Самоуправление необходимо для целенаправленного управляемого взаимодействия с объектом самообразования, что характерно для профессионального самообразования. Так как самоуправление развито и используется достаточно взрослым человеком [8], то сознательное целенаправленное профессиональное самообразование может осуществлять только взрослый индивид с вполне сформировавшимися самоуправленческими умениями. Таким образом, учащиеся вуза вполне обладают самоуправленческими навыками. Самоуправление является одним из принципиальных элементов системы, благодаря ему функционирует обратная связь в самообразовательном акте. Это, в свою очередь, позволяет доводить самообразовательный акт до логического конца. Исходя из сказанного, самоуправление - элемент, обеспечивающий процесс профессиональной самообразовательной деятельности, сохранность его, реализацию программ и целей. Если мотивация - это мотор, то самоуправление это элемент обратной связи автоматической системы, которая отслеживает и поддерживает режимы работы.

Последний компонент - внутренняя постоянная. Если продолжать сравнивать с автоматической системой, то это датчик, усилитель и устройство сравнения. Содержание ее составляют психологические процессы, характеристики и состояния. Все они относятся к внутреннему миру индивида, и в самообразовательном 
акте сохраняются постоянными. Отсюда появилось название. Конкретно, это развитые психические познавательные процессы (восприятие, внимание, память, мышление, воображение и интуиция). Это личностные психологические качества как воля, позитивные черты характера: трудолюбие, ответственность, самостоятельность и др. В эту же череду встраиваются психологические способности, в частности, понимание, а также состояния, в частности, зона актуального развития (ЗАР) [9].

Все перечисленные психологические процессы, способности, состояния, с одной стороны, ведут к успешному совершению акта самообразования, с другой стороны, внутренняя постоянная является основными ограничителями самообразования.

Рассмотри два ограничения. Самообразование осуществляется достаточно успешно, если оно происходит в ЗАР. Как только проблемы и задачи выходят из ЗАР, самообразование, вероятнее всего, заглохнет. Движение в зоне ближайшего развития (ЗБР), а это, как правило, творческие разработки, требует либо участия другого человека, либо значительные личные волевые усилия к продолжению процесса, что далеко не всегда получается.

Приведем второй пример. Мощным естественным ограничителем профессионального самообразования являются общие и специальные способности.

Всем известно, что, чем выше уровень способностей у человека, тем вероятнее его вступление на стезю самообразования. Гениальные люди практически всегда и всего достигают самообразованием [10], [11]. Выполнение профессионального самообразовательного акта сильно затягивается, а зачастую прекращается, если нет соответствующих способностей.

Таким образом, из анализа системы «готовности личности к профессиональному самообразованию» следуют выводы:

1. на часть компонент или их составляющих искусственно влиять не следует, они либо сформировались ранее (самоуправленческие умения), либо формируются в соответствие с учебным процессом (специальные знания и умения, относящиеся к профессиональной сфере);

2. часть составляющих компонент следует формировать с помощью информационных средств (мотивация, сведения о психологических процессах, состояниях, способностях, некоторых специфических методах обработки информации об объектах профессионального самообразования);

3. часть составляющих компонент следует форми- ровать, это специальные умения, которые нужно включать в учебную работу, приближенную к самообразовательной: курсовые, креативные задания, требующие самообразовательных усилий, дипломная работа, практика и др.;

4. требуется проверка степени сформированности компонентов системы.

Таким образом, наметились первоочередные задачи:

1. выяснить объем, характер и уточнить содержание специального учебного пособия по основам профессионального самообразования;

2. определить и разработать инструмент для выявления развитости или успешности развития компонентов ГЛПС;

3. наметить дисциплины, в рамках которых поддерживается реализация мероприятий и средств самообразовательного характера, как в содержательном плане, так и в плане отслеживания результатов.

С этой целью были разработан план и проведен разведывательный эксперимент, в процессе которого был установлено следующие факты.

Измерения профессиональных знаний совпадало с положительными оценками по результатам сессий, защите курсовых проектов и работ, отчетах по практике. То есть в этом отношении результаты официального учебного процесса совпали с требованиями наращивания ГЛПС.

Измерения использования методов и приемов специальных СЗУ проводились на основании результатов выполнения курсовых проектов и работ, индивидуальных заданий, то есть всего объема работы, в которая включались специальные вопросы или действия, которые квалифицировалась как самообразовательные.

Развитость готовности к профессиональному самообразованию оценивалась по характеру и направленности выпускной квалификационной работы и заключительному тесту, который проводился во время подготовки дипломной работы.

Выявилась роль стержневого (профессионального) интереса [12]. Интерес можно разделить на общий и стержневой (профессиональный). Пока изучаются предметы общего цикла - гуманитарные и естественно-научные, интерес поддерживается общий. Это состояние продолжается на первом и втором курсе. Стержневой интерес осознанно практически не проявляется. Как только в учебном процессе начинают превалировать дисциплины общепрофессионального и профессионального циклов, то начинает проявляться стержневой интерес, который и стимулирует обучение на последних 
кypcax.

Заметим, что стержневой интерес влияет на отсев студентов. Отмечено, чем раньше сформируется этот интерес, тем вероятнее то, что студент не бросит учебу. Так как на начальных курсах бросали учиться именно те учащиеся, у которых интерес не определился.

Определенно удалось выявить что:

1. необходим специальный предмет основы профессионального самообразования на первом курсе:

2. все учебные предметы, содержащие курсовые работы (проекты) - это потенциальные средства;

3. ежегодная практика - должна содержать элементы ГЛПС, в частности, вопросы непосредственной коммуникации с руководителями, на предмет использования теми самообразования. Задания могут быть и другими.

\section{Практическая значимость результатов экспериментального исследования}

Примем во внимание, что экспериментальная работа происходила в рамках проекта, который был рассчитан на два года, но затянулся на три. Не было контрольных групп, что должно значительным образом снижать ее ценность. Однако определенные выводы по практической значимости приведены с учетом и предыдущей работы.

Во-первых, была уточнена структура специального пособия по самообразованию студентов технического вуза системы готовности к профессиональному самообразованию. Во-вторых, были определена и отражена в сознании студентов роль учебного самообразования с его дидактическими средствами. В-третьих, указана роль системы готовности к профессиональному самообразованию как средства профессионального роста. В-четвертых, уточнена мотивация профессионального самообразования, выделены доминантные мотивы.

Попутно еще раз подтверждено, что с прямое социальное взаимодействие и образование постоянно действующих социальных групп помогает адаптации студентов, учебе в вузе и сохранности контингента.
Оказалось, что значительным образом следует усилить понимание роли профессионального самообразования в жизнедеятельности выпускника вуза.

Установили, что пропедевтический курс по самообразованию для студентов заочной формы обучения в вузе (как и дистанционной) необходим. Он

1. знакомит студентов с профессиональным самообразованием, как формой существования и способом успешно закончить обучение в вузе, а также способом постоянно повышать свою квалификацию в дальнейшей работе;

2. представляет вместе с формами дидактические средства самообразования во время учебы, а также и в последствие во время работы;

3. подготавливает основу становления готовности выпускника к профессиональному самообразованию.

\section{Выводы}

В настоящей действительности происходит ряд инновационных педагогических процессов. В частности, внедряется дистанционная форма обучения. Так как дистанционная форма обучения по некоторым факторам еще более близка к самообразовательной деятельности, чем заочная форма, то выводы данной работы актуальны и для неё.

Предусматривать в учебном плане пропедевтические курсы по самообразованию, которые бы отвечали условиям, приведенным выше.

Следует повышать в сознании студентов значимость профессионального самообразования как средства совершенствования профессиональных качеств, возможности профессионального роста, необходимости постоянного поддержания собственной высокой квалификации.

Необходимо с первого курса поддерживать познавательный интерес стержневого (профессионального) типа.

Рекомендуется на первом курсе организовывать (по возможности) прямое взаимодействие всех участников с целью создания межличностных контактов.

\section{ЛИТЕРАТУРА}

1. ФГОС 15.03.05. Конструкторско-технологическое обеспечение машиностроительных производств. URL.-http://classinform.ru/fgos/15.03.05konstruktorsko-tekhnologicheskoe-obespechenie-mashinostroitelnykh-proizvodstv.html

2. ФГОС 09.03.01. Информатика и вычислительная техника. URL.-https://www.garant.ru/products/ipo/prime/doc /71228468/1.

3. Концепция «индустрия 4.0» URL. - http://siemens.rbc.ru/article2.html. - 2016

4. Калугин Ю.Е. Самообразование, содействие профессиональному самообразованию: монография. - Челябинск: Издательский центр ЮУрГу, 2009. - 187 с 
5. Селевко Г.К. Современные образовательные технологии. - М.: Народное образование.-1998.- 252 с.

6. Заочное обучение. URL.- https://ru.wikipedia.org/wiki/Заочное_обучение.

7. Ковалев В.И. Мотивы поведения и деятельности - М.: 1988. Наука. - 192 с.

8. Калугин Ю.Е., Киселева Т.В. Мотивация профессионального самообразования. -//Альманах современной науки и образования. $2014 .-$ № 10 (88).- С. $77-79$

9. Выготский Л.С. Проблемы обучения и развития в школьном возрасте. - М.: Издательский Дом Шалвы Амонашвили, 1996. - С. 107-123.

10. Карцев В.В. Максвелл. - М.: Молодая гвардия, 1974. - 336 с.

11. Сноу Ч.П. Портреты и размышления. - М.: Прогресс, 1985. - 368 с.

12. Ильин Е.П. Мотивация и мотивы. - СПб.: Питер, 2000. - 512 с.

( К Калугин Юрий Евгеньевич, Калугин Юрий Евгеньевич (prokhorovav@susu.ru).

Журнал «Современная наука: актуальные проблемы теории и практики»

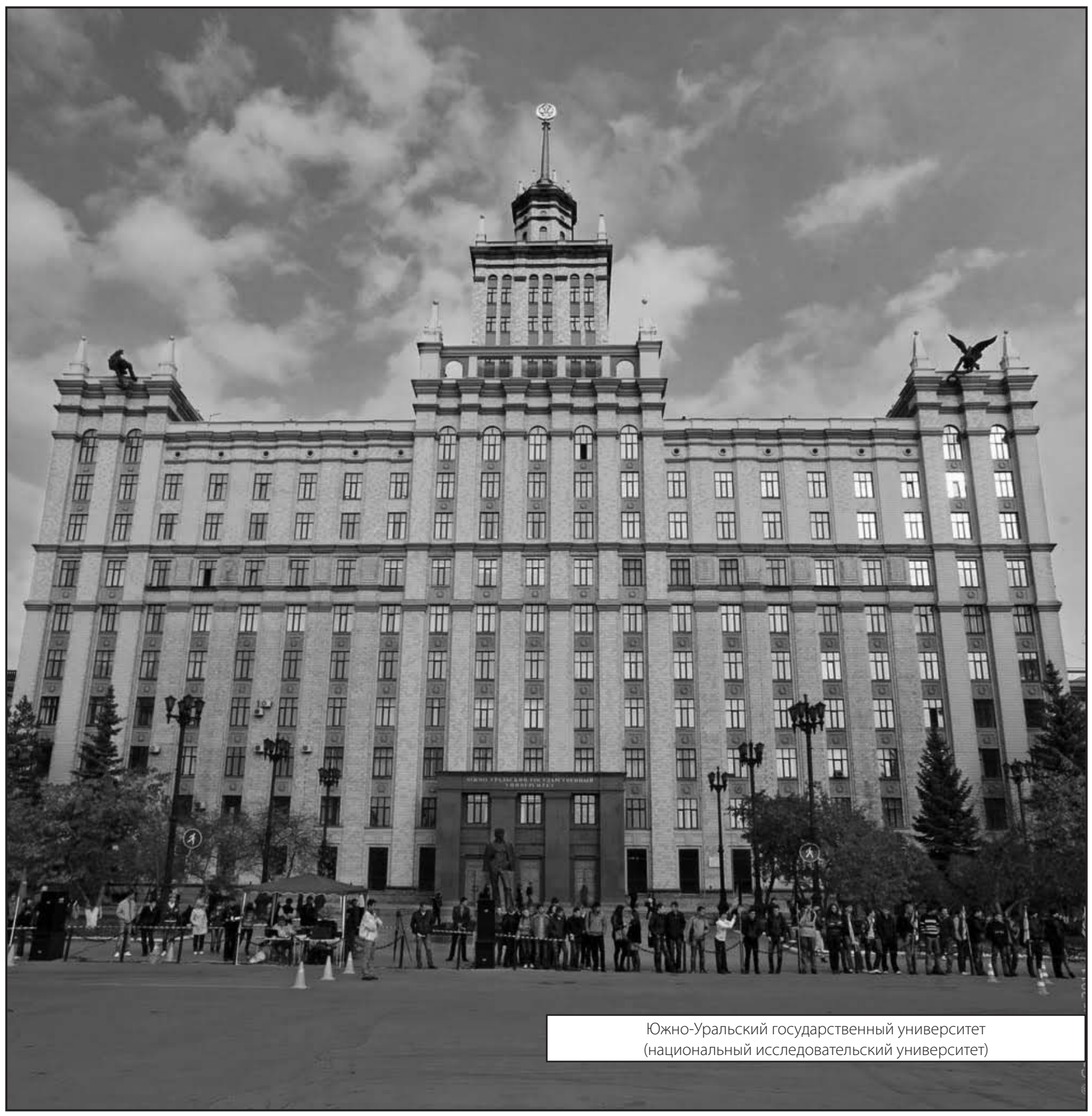

